Jürgen Stamm

\title{
Die Prinzipien und Grundstrukturen des Zwangsvollstreckungsrechts
}

\author{
Ein Beitrag zur Rechtsvereinheitlichung auf europäischer Ebene
}

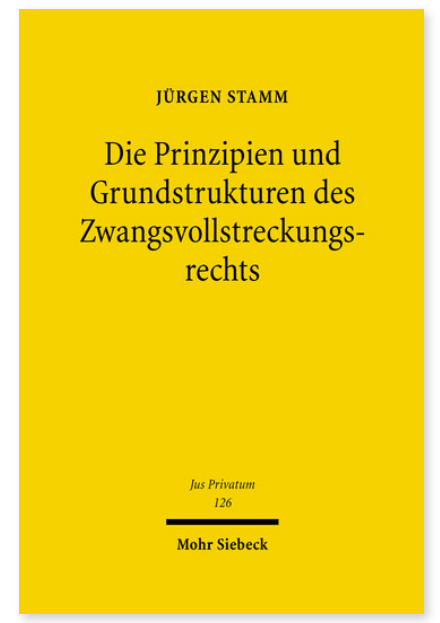

2007. XXXVIII, 703 Seiten. JusPriv 126

ISBN 978-3-16-151203-2

DOI 10.1628/978-3-16-151203-2

eBook PDF 174,00€

ISBN 978-3-16-149246-4

Leinen $174,00 €$
Im Prozess der europäischen Einigung ist das Zwangsvollstreckungsrecht derzeit eher als ein Stiefkind zu bezeichnen. Die Schwierigkeiten liegen hauptsächlich darin begründet, dass es bislang in den meisten europäischen Ländern an einer dogmatischen Aufarbeitung der Prinzipien und der Grundstrukturen der Zwangsvollstreckung mangelt. Vor diesem Hintergrund verfolgt Jürgen Stamm den Ansatz, das Vollstreckungsrecht mit seinen vermeintlichen Eigenarten auf die bekannten Strukturen des Zivilrechts und des öffentlichen Rechts zurückzuführen. Eine angemessene Schnittstellenbildung zwischen privatem und öffentlichem Recht eröffnet die Chance, die tradierten Prinzipienkataloge dieser beiden Rechtsgebiete für das Vollstreckungsrecht fruchtbar zu machen. Dabei liefert die Betrachtung der Vollstreckungsordnungen der europäischen Nachbarn wertvolle Impulse für eine Modernisierung des deutschen Vollstreckungsrechts in Richtung auf eine europäische Rechtsvereinheitlichung. Die Zielsetzung der Untersuchung liegt damit sowohl in der dogmatischen Aufarbeitung der Prinzipien und Grundstrukturen des deutschen Vollstreckungsrechts als auch zugleich in der Schaffung eines einheitlichen Verständnismodells für ein künftiges europäisches Vollstreckungsrecht.

Jürgen Stamm Geboren 1968; Studium der Rechtswissenschaften in Münster; 2000 Promotion; 2006 Habilitation; Professor für Bürgerliches Recht, Zivilprozessrecht, Internationales Privat- und Verfahrensrecht an der Universität Tübingen.
Jetzt bestellen:

https://mohrsiebeck.com/buch/die-prinzipien-und-grundstrukturen-des-zwangsvollstreckungsrechts-9783161512032? no_cache=1

order@mohrsiebeck.com

Telefon: +49 (0)7071-923-17

Telefax: +49 (0)7071-51104 